\section{The Effects of Individual Environmental Concerns on Willingness to Pay for Sustainable Plant Attributes}

\author{
Hayk Khachatryan ${ }^{1}$ \\ Food and Resource Economics Department and Mid-Florida Research \\ and Education Center, University of Florida, 2725 S. Binion Road, \\ Apopka, FL 32703

\section{Ben Campbell} \\ Department of Agricultural and Resource Economics, University of \\ Connecticut, 3107 Horsebarn Hill Road, Storrs, CT 06269
}

\section{Charles Hall}

Department of Horticultural Sciences, Texas A\&M University, College Station, TX 77843

\section{Bridget Behe}

Department of Horticulture, Michigan State University, East Lansing, MI 48824

\section{Chengyan Yue \\ Department of Horticultural Science and Department of Applied Economics, University of Minnesota, St. Paul, MN 55108}

\section{Jennifer Dennis \\ Departments of Horticulture and Landscape Architecture and Agricultural Economics, Purdue University, West Lafayette, IN 47907}

Additional index words. altruistic concerns, biospheric concerns, edible plants, egoistic concerns, environmental attributes, ornamental plants

\begin{abstract}
This study adds to the consumer choice literature by linking consumers' environmental concern (EC) orientations (egoistic, altruistic and biospheric) to willingness to pay (WTP) premiums for proenvironmental attributes. Results from a mixed-ordered probit model showed that individuals were willing to pay a premium for energy-saving production practices $(\mathbf{\$ 0 . 1 3 1})$, non-plastic containers such as compostable (\$0.227), plantable (\$0.122), and recyclable $(\$ 0.155)$, and locally grown plants $(\mathbf{\$ 0 . 2 2 2})$. Individuals scoring high on the EC scale expressed higher WTP across all attributes-\$0.148 for energy-saving practices, $\$ 0.288$ for locally grown plants, and \$0.255, \$0.143, and \$0.175 for compostable, plantable, and recyclable containers, respectively. Using the results, we discuss the practical implications for nursery and garden stores (i.e., communicating product attributes related information to consumers).
\end{abstract}

The U.S. green industry, which includes nursery and greenhouse growers, input suppliers, wholesalers, mass-merchandisers, independent retail operations, and landscape design and maintenance firms, has experienced considerable growth and modernization over the last two decades. With recent economic downturns (2007-09), however, declines in consumers' discretionary expenditures (such as purchasing of ornamental plants) affected the industry's financial performance (Hall, 2010; IBISWorld Reports,

Received for publication 25 June 2013. Accepted for publication 14 Nov. 2013.

${ }^{1}$ To whom reprint requests should be addressed; e-mail hayk@ufl.edu. 2013a, 2013b). As a result of an increasing number of home foreclosures and escalating unemployment rates, coupled with heightened competition, industries such as florists, nursery and garden stores faced declining revenue and profit margins since 2006 (IBISWorldReports, 2013a, 2013b). Slim margins ranging from $0.2 \%$ to $2 \%$ forced many nurseries and garden stores to either reduce the number of employees or end entire operations (IBISWorldReports, 2013a). From 2006 to 2013 (with the exception of 2012), nursery and garden stores industry revenues declined, ranging from $-0.2 \%$ to $-7.7 \%$ (IBISWorldReports, 2013a). As the green industry struggles to cope with declining demand (since 2006) and tight profit margins $(0.2 \%$ to $2 \%$; IBISWorldReports, 2013a), increased attention on consumer preferences and factors that influence individual choice behavior is needed. Recently, marketing of products with environmentally friendly characteristics has become a promising strategy to attract a specific segment comprised of environmentally conscious consumers (Behe et al., 2013; Royne et al., 2011).

One of the strategies to maximize customer share in the environmentally conscious consumer market segment is centered on investigating individuals' understanding and concerns about contemporary environmental issues and offering products that are designed to mitigate selected environmental problems. Investigation of individuals' EC scores and their effects on choice behavior may provide useful implications to promote environmental benefits that green industry products and services offer to consumers (e.g., plants grown using sustainable production methods or grown in recyclable, compostable, and plantable containers). Empirically, a widely used practice for assessing the relationship between consumer demand and environmentally friendly goods is investigating the WTP price premiums for underlying product attributes. Previous literature has mainly focused on the effects of product attributes or consumers' demographic characteristics on choice behavior.

For example, Moon et al. (2002) investigated consumers' WTP a premium for agricultural commodities that were produced with environmentally friendly technology. The survey participants were asked whether and how much above the current price they would be willing to pay for commodities that were produced with techniques not harmful to the environment. Willingness to pay responses were used as a dependent variable and analyzed with respect to a number of sociodemographic variables (income, age, gender, marital status, education, etc.) in an ordered logit model. The authors did not discuss specific WTP but reported predicted probabilities to pay a premium for environmentally benign production techniques, which may provide incentives for agricultural producers to adopt environmentally friendly practices.

Loureiro et al. (2001) examined factors affecting consumers' preferences for ecolabeled and organic apples by focusing on differences in sociodemographic variables (presence of children in the household, income, family size, and beliefs about food safety and environmental quality). Using a multinomial logit model, the authors found that an organic characteristic was preferred to eco-labeling when food safety, environment quality, and presence of children in the households are considered. In a relevant study (Blend and van Ravenswaay, 1999), the authors report that more than one-third of the surveyed households were willing to pay a $\$ 0.40$ per pound $(0.45 \mathrm{~kg})$ premium for ecolabeled apples. Environmental claims in the form of eco-labeling were also investigated for seafood products (Wessells et al., 1999). A contingent valuation framework (focusing 
on physical characteristics of seafood) was used, in which the respondents chose between certified and uncertified seafood. However, similar to the studies briefly reviewed here, individual-specific variables with environmental focus were not included in the empirical model.

The present study contributed to the literature regarding consumer choice behavior by introducing a set of attitudinal variables that allows examining the effects of individuals' environmental attitudes on individual choice decision-making. Specifically, we investigated the relationship between the EC scale, its egoistic, altruistic, and biospheric orientations, and WTP price premiums for 1) plants grown using sustainable, energy- and water-saving production methods; 2) plants grown in compostable, plantable, and recyclable containers; and 3) plants grown locally as opposed to being imported.

Environmental concerns and consumer preferences. Development of methodologies to measure environmental attitudes dates back to the early 1970s (Weigel, 1983). Relatively recent contributions by Stern et al. (1993), Stern and Dietz (1994), and Weigert (1997) extended the earlier discussions of EC scale, its causal inferences, and the association with proenvironmental behavior by suggesting multiple underlying mechanisms for individuals' concerns toward environmental problems. In particular, Stern et al. (1993) and Stern and Dietz (1994) suggested that attitudes about environmental issues can be explained by three relevant but distinct motivations: concern for self, concern for other people, and concern for the biosphere. Previous findings that the EC scale consists of three underlying factors were further investigated by Schultz (2001). Analyzing data from a diverse sample of the general public and college students from 10 countries, the authors validated the earlier evidence for the three-way classification of ECs: egoistic, altruistic, and biospheric subscales. Conclusions from further research on the topic by Schultz et al. (2005) allow generalizing that individuals' concern is based on the extent to which they perceive the relationship between themselves and other people or between themselves and the globe/biosphere.

Although the EC scale used in our study is adapted from the framework developed in Schultz (2001), it is principally based on the value-belief-norm (VBN) theory of proenvironmental behavior (Stern, 2000; Stern et al., 1993, 1999; Stern and Dietz, 1994). The VBN theory combines value and normactivation theories with the new environmental paradigm to create a causal or mediation chain, a structure that helps analyze correlations among individuals' values, beliefs, proenvironmental norms. and behavioral outcomes (de Groot and Steg, 2010; Milfont et al., 2010). The extent to which individuals are concerned about contemporary environmental problems may influence preferences and choice decision-making for products that offer environmentally friendly characteristics. For example, preferences for goods produced using environmentally sustainable production methods may be different for the individuals who assign greater importance to the environmental consequences. In the context of the present study, one such behavioral outcome is consumers' choice for plants that are grown using environmentally friendly production practices (i.e., sustainable, energy- and water-saving production methods), offered in non-conventional containers (i.e., compostable, plantable, and recyclable) and produced locally as opposed to being imported or produced elsewhere within the United States.

Summary of hypotheses. Based on the prior studies that have linked individuals' ECs with engagement in proenvironmental activities (de Groot and Steg, 2010; Hansla et al., 2008; Milfont et al., 2010; Stern et al., 1993), we hypothesized that individuals with higher (above-average) EC total scores (i.e., with no egoistic, altruistic, and biospheric orientations) would be willing to pay higher price premiums for proenvironmental production-related attributes such as grown using sustainable, energy-/water-saving production methods as opposed to conventional production methods (Hypothesis 1). Furthermore, we hypothesized that the WTP for production methods-related attributes will differ based on egoistic, altruistic, and biospheric orientations of the EC scale (Hypothesis 2). We also hypothesized that individuals scoring high (above average) on the EC scale would be willing to pay higher price premiums for plants in environmentally friendly (i.e., compostable, plantable, and recyclable as opposed to plastic) containers (Hypothesis 3 ) and that the WTP would differ by EC orientations (Hypothesis 4). Finally, we hypothesized that individuals with higher (above average) EC total scores would require higher price discounts for imported plants and would be willing to pay higher price premiums for locally produced plants (compared with those grown in country) (Hypothesis 5) and that the WTP and price discounts would vary based on individual EC orientations discussed previously (Hypothesis 6).

\section{Methodology}

Data description. The data used in this study were collected as part of a larger study designed to investigate the recent market trends for horticultural products in the United States and Canada. An online survey was used because of its advantages compared with other survey techniques, namely faster distribution, convenience, more accurate information with less human error, and less expensive (Dillman et al., 2009). The online survey was conducted by consumer marketing company, Global Market Insite, Inc. (GMI) (Bellevue, WA), which maintains a database of U.S. and Canadian consumers. The GMI's panel of respondents was contacted by e-mail and invited to participate in the survey. Respondents willing to partici- pate were directed to an online survey link and proceeded to take the survey. A total of 2511 consumers were surveyed with $68 \%$ and $32 \%$ of respondents being from the United States and Canada, respectively. The 48 contiguous states and all Canadian provinces were represented in the survey.

The sample demographics were similar to the average census demographics for the United States and Canada. The U.S. sample had an average age of 35.8 years (compared with the U.S. Census estimate of 37.2 years) with $78.1 \%$ Caucasian (U.S. Census average $78.1 \%$ ). The U.S. sample was a little less representative in terms of average household income, $\$ 65,273$ vs. $\$ 52,762$ (Census), and gender, $58.3 \%$ male vs. $49.2 \%$ male (Census). With regard to the Canadian sample, age (sample, 42.7 years vs. Census, 39.7 years), average household income (sample, \$66,747 vs. Census, $\$ 69,860$ ), and gender (sample, $49.6 \%$ male vs. Census, $48.6 \%$ male) were very similar to the Canadian population averages. The means by which we asked the ethnicity question, in line with the U.S. Census methodology, is not directly comparable to the Canadian census given the way the question is asked and how responses are calculated; however, rough calculations indicate that the percent "Caucasian" in Canada is $\approx 80 \%$, which is slightly less than our sample average of $86 \%$.

Environmental concerns scale. To account for differences in WTP estimates by these three relevant but different orientations of environmental concerns, the respondents were asked to complete the EC scale (Schultz, 2001) as part of the questionnaire. Following Schultz (2001), the EC scale consisted of 12 items, four of which had egoistic orientation (i.e., concerned about the environment for one's own self), the second set of four items had altruistic orientation (i.e., concerned about environmental problems for the sake of others), and finally, the third set of four items had biospheric orientation (i.e., concerned about environmental problems for the globe/biosphere). The participants were asked to use a Likert scale $(1=$ not important to $5=$ supreme importance) to indicate the extent to which they were concerned about environmental problems for each of the 12 items included in the EC scale. The EC total score is the average of all 12 items in the EC scale. EC-egoistic, ECaltruistic, and EC-biospheric scores are the average scores of the four items in each of the three orientations - egoistic, altruistic, and biospheric. Internal reliability (Cronbach's alpha statistic) for four egoistic items was $0.93,0.90$ for four altruistic items, and 0.93 for four biospheric items. (Cronbach's alpha is a measure of internal reliability expressed as a number between 0 and 1 , which describes the degree to which all of the items in a scale measure the same concept.) With average scores of mean $=3.89(\mathrm{SD}=0.91)$ for egoistic, mean $=3.96(\mathrm{SD}=0.88)$ for altruistic, and mean $=3.81(\mathrm{SD}=0.93)$ for biospheric orientation, the Cronbach's alpha reliability statistics are comparable with previous 
literature (de Groot and Steg, 2008; Schultz, 2001).

After estimating the initial model (base model, without the EC scale), we estimated two more models, one for the respondents with above-average total EC scores (implies the total EC score was higher than the average total EC score) and one for respondents with below-average total EC scores (implies the total EC score was lower than the average total EC score). Finally, we examined each of the orientations (ECegoistic, EC-altruistic, and EC-biospheric) by creating subsamples based on "aboveaverage" and "below-average" scores for each orientation of the EC scale. We then modeled each subgroup with a separate model (i.e., above-average egoistic score, belowaverage egoistic score, above-average altruistic score, below-average altruistic score, above-average biospheric score, and belowaverage biospheric score)

Choice scenario design. To investigate consumers' WTP for plant attributes, we used a conjoint experimental design in the online survey. Conjoint experiments have been broadly used to analyze consumers' preference structure for a wide range of ornamental products, including landscapes (Behe et al., 2005a), Christmas trees (Behe et al., 2005b), plant containers (Hall et al., 2010), mixed flowering annual containers (Mason et al., 2008), and native plants (Zagaden et al., 2008), to name only a few. The conjoint analysis approach allows investigating the preference for certain product attributes as well as the relationship between choice behavior and sociodemographic variables.

The choice-based conjoint design included three types of plants, three price levels, four production practice levels, four container types, and three origins of production (Table 1). Our goal in selecting three different types of plants (tomato, basil, and chrysanthemum) was not to identify specific preferences for the plants shown, but rather to better understand if preference varied by plant type (food-producing, edible, and ornamental plants, respectively). Chrysanthemum was the base category in the regression analysis; thus, the coefficients for tomato and basil plants are interpreted in relation to that of chrysanthemum. Realistic price levels were set in equal increments $(\$ 1.99, \$ 2.49$, and $\$ 2.99$ per plant) for a 4-inch $(10.16 \mathrm{~cm})$ container containing a transplant of each plant type. These price points were representative of the retail price of plants in 4-inch containers found throughout U.S. and Canadian markets during Spring 2011.

Table 1. Five plant attributes and levels of each included in a 2011 online survey of consumer preferences for plant attributes.

\begin{tabular}{ll}
\hline Plant attributes & \multicolumn{1}{c}{ Attribute levels } \\
\hline Price & $\$ 1.99, \$ 2.49$, and $\$ 2.99$ per plant \\
Plant type & Tomato, basil, and chrysanthemum \\
Production methods & Sustainable, energy-saving, water-saving, and conventional \\
Container types & Compostable, plantable, recyclable, and plastic \\
Origin of production & Local, imported, and domestic (i.e., grown within this country) \\
\hline
\end{tabular}

willingness to purchase, respondents clicked on the line scale with the underlying computer program assigning a numerical value depending on where the respondent clicked. As such, the line scale can be coded as $0=$ "definitely would not purchase," ..., $100=$ "definitely would purchase."

In addition to the plant choice exercise, the survey asked a variety of questions pertaining to horticultural purchasing habits and demographics (including income, education, marital status, age, gender, household characteristics, and ethnicity). Purchase behavior questions consisted of whether they were the primary shopper in the household, the types of stores generally shopped in, and their tendencies in purchasing local and organic produce.

Econometric model. A mixed effects ordered probit model (Frechette, 2001; RabeHesketh et al., 2000; Sribney, 1995), which controls for individual-specific effects when analyzing limited dependent variables, was used to estimate the WTP for plant attributes by different EC orientations (e.g., egoistic, altruistic, and biospheric). Following Boyle et al. (2001) and Yue et al. (2010), the choice model, which assumes linear preferences over product attributes included in the choice design, can be presented as the following equation:

$$
V(\cdot)=\alpha p+\beta \mathbf{A}+v+\varepsilon
$$

where $V(\cdot)$ represents an indirect utility function, $\mathbf{A}$ is a column vector that includes product attributes (plant type, production practices, container types, origin of production), and $p$ is the price in the choice design. The coefficient $\alpha$ represents the marginal utility of money, and the coefficient $\beta$ is the weight assigned to the product attributes. The estimated coefficients for $\alpha$ and $\beta$ are used in Eq. (2) to estimate WTP for the each of the attributes. The random individual effect is captured by $v$, which is assumed to be normally distributed with mean zero and SD $\sigma_{v}$, and $\varepsilon$ is the random error term. WTP differences between attributes $i$ and $j$ and confidence intervals (using the Delta method described in Greene, 2012) were calculated using the following equation:

$$
W T P_{i-j}=b\left(A_{i}-A_{j}\right) / \alpha
$$
scale (i.e., no numbers shown) with the three scale markers, indicating "definitely would not purchase" at the beginning, "may or may not purchase" at the middle, and "definitely would purchase" at the end. Numerical end points and intermediate numbers were not given because adding numerical values to the scale has been shown to bias results (Lawless and Heyman, 1999). To indicate their desired

where $\alpha$ and $\beta$ represent estimated coefficients for price and product attributes, respectively, and $i$ and $j$ denote different levels of attributes.

\section{Results}

Model 1 (base model) includes the attributes presented in Table 1 and the respondents' demographic measures such as income, age, gender, race, education level, residence area, household size, number of children in household, and country-United States/ Canada (Table 2). Although Model 2 includes the same set of variables as in Model 1, the estimation included subsample of respondents with above-average EC scores (i.e., only observations with higher than average EC score 


\begin{tabular}{|c|c|c|c|c|c|c|c|c|c|c|}
\hline \multirow[b]{2}{*}{ Variables } & \multicolumn{2}{|c|}{$\begin{array}{c}\text { Model 1 } \\
\text { (base model) }\end{array}$} & \multicolumn{2}{|c|}{$\begin{array}{c}\text { Model } 2 \\
\text { (EC-total score) }\end{array}$} & \multicolumn{2}{|c|}{$\begin{array}{c}\text { Model } 3 \\
\text { (EC-egoistic) }\end{array}$} & \multicolumn{2}{|c|}{$\begin{array}{c}\text { Model } 4 \\
\text { (EC-altruistic) }\end{array}$} & \multicolumn{2}{|c|}{$\begin{array}{c}\text { Model } 5 \\
\text { (EC-biospheric) }\end{array}$} \\
\hline & Coefficient & $P$ value & Coefficient & $P$ value & Coefficient & $P$ value & Coefficient & $P$ value & Coefficient & $P$ value \\
\hline \multicolumn{11}{|l|}{ Attributes } \\
\hline Price & -0.291 & 0.000 & -0.296 & 0.001 & -0.300 & 0.001 & -0.288 & 0.001 & -0.297 & 0.001 \\
\hline Sustainable & -0.003 & 0.856 & 0.001 & 0.950 & 0.007 & 0.781 & 0.006 & 0.783 & 0.008 & 0.722 \\
\hline Energy-saving & 0.038 & 0.011 & 0.044 & 0.020 & 0.041 & 0.085 & 0.041 & 0.065 & 0.044 & 0.039 \\
\hline Water-saving & 0.010 & 0.486 & 0.011 & 0.560 & 0.013 & 0.576 & 0.009 & 0.674 & 0.014 & 0.517 \\
\hline Compostable & 0.066 & 0.000 & 0.075 & 0.001 & 0.072 & 0.003 & 0.079 & 0.001 & 0.080 & 0.001 \\
\hline Plantable & 0.036 & 0.018 & 0.042 & 0.020 & 0.030 & 0.217 & 0.038 & 0.088 & 0.038 & 0.074 \\
\hline Recyclable & 0.045 & 0.003 & 0.052 & 0.001 & 0.034 & 0.153 & 0.047 & 0.035 & 0.050 & 0.019 \\
\hline Locally produced & 0.065 & 0.000 & 0.085 & 0.001 & 0.097 & 0.001 & 0.099 & 0.001 & 0.092 & 0.001 \\
\hline Imported & -0.442 & 0.000 & -0.523 & 0.001 & -0.545 & 0.001 & -0.567 & 0.001 & -0.572 & 0.001 \\
\hline \multicolumn{11}{|l|}{ Plant types } \\
\hline Tomato & 0.053 & 0.000 & 0.086 & 0.001 & 0.110 & 0.001 & 0.129 & 0.001 & 0.135 & 0.001 \\
\hline Basil & -0.082 & 0.000 & -0.051 & 0.001 & -0.015 & 0.462 & 0.001 & 0.959 & -0.002 & 0.925 \\
\hline \multicolumn{11}{|l|}{ Demographics } \\
\hline Income & 0.067 & 0.000 & 0.025 & 0.001 & 0.013 & 0.152 & 0.024 & 0.039 & 0.030 & 0.030 \\
\hline Age & -0.005 & 0.000 & -0.006 & 0.001 & -0.004 & 0.029 & -0.006 & 0.001 & -0.006 & 0.001 \\
\hline Gender & 0.219 & 0.000 & 0.161 & 0.001 & 0.052 & 0.269 & 0.101 & 0.024 & 0.126 & 0.005 \\
\hline Caucasian & -0.184 & 0.006 & -0.028 & 0.510 & -0.161 & 0.003 & -0.101 & 0.096 & -0.110 & 0.059 \\
\hline Education & 0.505 & 0.000 & 0.301 & 0.001 & 0.364 & 0.001 & 0.364 & 0.001 & 0.335 & 0.001 \\
\hline Residence area & 0.168 & 0.000 & -0.046 & 0.300 & -0.095 & 0.086 & -0.078 & 0.176 & -0.070 & 0.193 \\
\hline Country & -0.309 & 0.000 & 0.038 & 0.360 & 0.031 & 0.574 & 0.065 & 0.207 & 0.074 & 0.148 \\
\hline Household size & 0.086 & 0.000 & 0.040 & 0.001 & -0.010 & 0.560 & 0.002 & 0.898 & 0.010 & 0.616 \\
\hline No. of children & 0.110 & 0.000 & 0.000 & 0.980 & 0.002 & 0.902 & 0.007 & 0.680 & 0.010 & 0.560 \\
\hline Random individual effect & 0.512 & 0.000 & 0.480 & 0.001 & 0.476 & 0.001 & 0.476 & 0.001 & 0.474 & 0.001 \\
\hline Constant 1 & -13.270 & 0.000 & -14.546 & 0.001 & -10.405 & 0.001 & -14.590 & 0.001 & -14.513 & 0.001 \\
\hline Constant 2 & -12.089 & 0.000 & -13.548 & 0.001 & -9.431 & 0.003 & -13.611 & 0.001 & -13.543 & 0.001 \\
\hline Constant 3 & -11.739 & 0.000 & -13.229 & 0.001 & -9.148 & 0.004 & -13.318 & 0.001 & -13.246 & 0.001 \\
\hline Constant 4 & -11.444 & 0.000 & -12.958 & 0.001 & -8.880 & 0.005 & -13.043 & 0.001 & -12.977 & 0.001 \\
\hline Constant 5 & -11.188 & 0.000 & -12.726 & 0.001 & -8.673 & 0.006 & -12.831 & 0.001 & -12.761 & 0.001 \\
\hline Constant 6 & -10.816 & 0.000 & -12.398 & 0.001 & -8.346 & 0.008 & -12.507 & 0.001 & -12.434 & 0.001 \\
\hline Constant 7 & -10.302 & 0.000 & -11.923 & 0.001 & -7.877 & 0.012 & -12.040 & 0.001 & -11.971 & 0.001 \\
\hline Constant 8 & -9.878 & 0.000 & -11.519 & 0.001 & -7.495 & 0.017 & -11.656 & 0.001 & -11.588 & 0.001 \\
\hline Constant 9 & -9.429 & 0.000 & -11.089 & 0.001 & -7.064 & 0.025 & -11.231 & 0.001 & -11.165 & 0.001 \\
\hline Constant 10 & -8.966 & 0.000 & -10.616 & 0.001 & -6.591 & 0.036 & -10.754 & 0.001 & -10.693 & 0.002 \\
\hline No. of observations & 38,798 & & 23,503 & & 15,456 & & 18,064 & & 19,663 & \\
\hline $\begin{array}{l}\text { Likelihood ratio } \\
\qquad \chi^{2}(20)\end{array}$ & $2,367.95$ & & $1,788.70$ & & $1,259.35$ & & $1,552.82$ & & $1,705.85$ & \\
\hline Log likelihood & $-78,213$ & & $-47,545$ & & $-30,814$ & & $-36,149$ & & $-39,493$ & \\
\hline
\end{tabular}

Note: Statistically significant coefficients $(P$ values $<0.01$ and 0.05$)$ are presented in bold.

$\mathrm{EC}=$ environmental concern.

were included). In contrast, Model 1 is estimated using the entire sample without separating the observations into subsamples based on the EC scores. Similarly, Models 3 to 5 include the same set of variables but observations with above-average ECegoistic, EC-altruistic, and EC-biospheric (i.e., only observations with higher than average EC-egoistic, EC-altruistic, and ECbiospheric scores were included).

Table 2 shows the results of the mixedeffect probit model for the base model and models with the "above-average" EC scores (Models 2 to 5). The coefficients for the price attribute are statistically significant across all models and, as expected, negatively associated with purchase likelihood ratings. Among production practices-related attributes (sustainable, energy-saving, and water-saving), the coefficients for sustainable and watersaving attributes were not statistically significant across all models. The coefficients for energy-saving attribute were positive and statistically significant across all models (with the exception of Model 4) implying that the respondents are more likely to give a preference for plants grown using energysaving practices compared with those grown using conventional practices. Among container characteristics-related attributes (compostable, plantable, and recyclable), the compostable attribute is positive and statistically significant across all models, suggesting the respondents are more likely to choose plants with compostable containers as opposed to plastic containers. The plantable attribute, however, is positive and significant for only Models 1 and 2. Similarly, with the exception of Model 3, the recyclable attribute is positive and significant across all models. Finally, the coefficients for locally produced attribute were statistically significant and positive across all models with a negative association between the imported attribute and purchase likelihood ratings (Table 2).

Model 6 corresponds to Model 2 with the only difference that the subsample is based on observations with lower than average EC scores (Table 3). Likewise, Models 7 to 9 include observations with below-average EC-egoistic,
EC-altruistic, and EC-biospheric scores. In Model 6, energy-saving, plantable, recyclable, and locally produced are not significantly different from 0 , which is different from the base model. In contrast to Model 2, the coefficients for energy-saving, plantable, recyclable, and locally produced are not significant in Model 6. The only significant coefficients in Models 7 to 9 were for price and imported with a negative association with purchase likelihood ratings.

WTP for production methods-related attributes. The results discussed previously, however, do not provide the WTP estimates that can be used by green industry firms for making pricing-related decisions. Using Eq. 2 , the initial coefficients were transformed into WTP values. The WTP results based on Model 1 (base model, without EC score categories; Table 4), show that consumers were willing to pay a $\$ 0.131$ premium for the energy-saving attribute. The results of the model with higher (above-average) EC total scores (Table 4, Model 2), however, show that these consumers were willing to pay a higher 
Table 3. Comparison of mixed ordered probit model coefficients between base model and models with lower scores in EC orientations.

\begin{tabular}{|c|c|c|c|c|c|c|c|c|c|c|}
\hline \multirow[b]{2}{*}{ Variables } & \multicolumn{2}{|c|}{$\begin{array}{c}\text { Model 1 } \\
\text { (base model) }\end{array}$} & \multicolumn{2}{|c|}{$\begin{array}{c}\text { Model } 6 \\
\text { (EC-total score) }\end{array}$} & \multicolumn{2}{|c|}{$\begin{array}{c}\text { Model } 7 \\
\text { (EC-egoistic) }\end{array}$} & \multicolumn{2}{|c|}{$\begin{array}{c}\text { Model } 8 \\
\text { (EC-altruistic) }\end{array}$} & \multicolumn{2}{|c|}{$\begin{array}{c}\text { Model } 9 \\
\text { (EC-biospheric) }\end{array}$} \\
\hline & Coefficient & $P$ value & Coefficient & $P$ value & Coefficient & $P$ value & Coef. & $P$ value & Coef. & $P$ value \\
\hline \multicolumn{11}{|l|}{ Attributes } \\
\hline Price & -0.291 & 0.000 & -0.296 & 0.000 & -0.258 & 0.000 & -0.268 & 0.000 & -0.287 & 0.000 \\
\hline Sustainable & -0.003 & 0.856 & -0.013 & 0.596 & -0.024 & 0.481 & -0.027 & 0.372 & -0.023 & 0.385 \\
\hline Energy-saving & 0.038 & 0.011 & 0.025 & 0.296 & 0.021 & 0.535 & 0.022 & 0.470 & 0.029 & 0.273 \\
\hline Water-saving & 0.010 & 0.486 & 0.007 & 0.768 & 0.007 & 0.840 & 0.013 & 0.673 & 0.010 & 0.716 \\
\hline Compostable & 0.066 & 0.000 & 0.054 & 0.023 & 0.056 & 0.098 & 0.047 & 0.117 & 0.048 & 0.071 \\
\hline Plantable & 0.036 & 0.018 & 0.027 & 0.262 & 0.025 & 0.451 & 0.018 & 0.542 & 0.028 & 0.297 \\
\hline Recyclable & 0.045 & 0.003 & 0.037 & 0.117 & 0.051 & 0.129 & 0.040 & 0.191 & 0.031 & 0.242 \\
\hline Locally produced & 0.065 & 0.000 & 0.033 & 0.109 & -0.005 & 0.859 & 0.006 & 0.824 & 0.014 & 0.542 \\
\hline Imported & -0.442 & 0.000 & -0.305 & 0.000 & -0.239 & 0.000 & -0.239 & 0.000 & -0.273 & 0.000 \\
\hline \multicolumn{11}{|l|}{ Plant types } \\
\hline Tomato & 0.053 & 0.000 & 0.001 & 0.968 & -0.054 & 0.112 & -0.064 & 0.035 & -0.050 & 0.062 \\
\hline Basil & -0.082 & 0.000 & -0.136 & 0.000 & -0.249 & 0.000 & -0.230 & 0.000 & -0.212 & 0.000 \\
\hline \multicolumn{11}{|l|}{ Demographics } \\
\hline Income & 0.067 & 0.000 & 0.058 & 0.000 & 0.147 & 0.000 & 0.044 & 0.000 & 0.029 & 0.003 \\
\hline Age & -0.005 & 0.000 & -0.003 & 0.454 & -0.001 & 0.417 & 0.003 & 0.058 & -0.002 & 0.554 \\
\hline Gender & 0.219 & 0.000 & 0.367 & 0.000 & 0.380 & 0.000 & 0.273 & 0.000 & 0.126 & 0.040 \\
\hline Caucasian & -0.184 & 0.006 & -0.120 & 0.090 & -0.564 & 0.000 & -0.163 & 0.003 & -0.135 & 0.161 \\
\hline Education & 0.505 & 0.000 & -0.008 & 0.908 & -0.113 & 0.103 & -0.094 & 0.117 & -0.023 & 0.751 \\
\hline Residence area & 0.168 & 0.000 & 0.085 & 0.111 & -0.094 & 0.132 & -0.040 & 0.449 & -0.136 & 0.073 \\
\hline Country & -0.309 & 0.000 & -0.402 & 0.000 & -0.041 & 0.525 & 0.110 & 0.015 & 0.194 & 0.008 \\
\hline Household size & 0.086 & 0.000 & 0.057 & 0.082 & 0.010 & 0.647 & 0.091 & 0.000 & 0.051 & 0.172 \\
\hline No. of children & 0.110 & 0.000 & 0.179 & 0.000 & -0.029 & 0.127 & -0.042 & 0.020 & 0.092 & 0.065 \\
\hline Random individual effect & 0.512 & 0.000 & 0.559 & 0.000 & 0.576 & 0.000 & 0.589 & 0.000 & 0.590 & 0.000 \\
\hline Constant 1 & -13.270 & 0.000 & -8.877 & 0.249 & -5.702 & 0.050 & 2.727 & 0.377 & -6.165 & 0.257 \\
\hline Constant 2 & -12.089 & 0.000 & -7.441 & 0.334 & -4.118 & 0.156 & 4.279 & 0.166 & -4.614 & 0.397 \\
\hline Constant 3 & -11.739 & 0.000 & -7.032 & 0.361 & -3.684 & 0.205 & 4.706 & 0.127 & -4.179 & 0.443 \\
\hline Constant 4 & -11.444 & 0.000 & -6.691 & 0.385 & -3.326 & 0.252 & 5.066 & 0.101 & -3.834 & 0.482 \\
\hline Constant 5 & -11.188 & 0.000 & -6.387 & 0.406 & -3.028 & 0.297 & 5.370 & 0.082 & -3.526 & 0.518 \\
\hline Constant 6 & -10.816 & 0.000 & -5.942 & 0.440 & -2.530 & 0.384 & 5.840 & 0.058 & -3.065 & 0.574 \\
\hline Constant 7 & -10.302 & 0.000 & -5.357 & 0.486 & -1.891 & 0.515 & 6.434 & 0.037 & -2.465 & 0.651 \\
\hline Constant 8 & -9.878 & 0.000 & -4.889 & 0.525 & -1.367 & 0.638 & 6.940 & 0.025 & -1.969 & 0.718 \\
\hline Constant 9 & -9.429 & 0.000 & -4.381 & 0.569 & -0.828 & 0.776 & 7.444 & 0.016 & -1.458 & 0.789 \\
\hline Constant 10 & -8.966 & 0.000 & -3.919 & 0.610 & -0.336 & 0.908 & 7.909 & 0.010 & -0.983 & 0.857 \\
\hline No. of observations & 38,798 & & 15,295 & & 7,711 & & 9,599 & & 12,319 & \\
\hline $\begin{array}{l}\text { Likelihood ratio } \\
\chi^{2}(20)\end{array}$ & $2,367.95$ & & 601.22 & & 316.50 & & 364.72 & & 503.91 & \\
\hline Log likelihood & $-78,213$ & & $-30,064$ & & $-14,534$ & & $-18,378$ & & $-23,793$ & \\
\hline
\end{tabular}

Note: Statistically significant coefficients $(P$ values $<0.01$ and 0.05$)$ are presented in bold.

$\mathrm{EC}=$ environmental concern.

price premium $(\$ 0.148)$ for the same attribute, thus supporting Hypothesis 1 that individuals with higher EC total scores would be willing to pay a higher price premium for proenvironmental production-related attributes such as energy-saving methods. In line with this finding, the results of the model with lower (below-average) EC total scores (Model 6, Table 5) did not return a statistically significant result for any of the production method-related attributes.

Comparing results from models with (higher or lower) EC scores with the base model revealed some promising results, underscoring that individuals with higher EC scores generally were willing to pay higher premiums for selected proenvironmental production methods. However, closer investigation of different orientations of the EC showed that some WTP estimates may vary depending on individuals' egoistic, altruistic, or biospheric orientations of the EC. For example, the above-average biospheric orientation shows that consumers are willing to pay a $\$ 0.148$ premium for the energysaving attribute, whereas the respondents with above-average egoistic and aboveaverage altruistic scores are willing to pay $\$ 0.138$ and $\$ 0.143$, respectively. The coefficient estimates were not significant for watersaving and sustainable attributes, thereby Hypothesis 2 is partially supported.

WTP for potting containers-related attributes. The results in Table 4 (base model) also showed that the individuals were willing to pay a price premium for compostable $(\$ 0.227)$, plantable $(\$ 0.122)$, and recyclable $(\$ 0.155)$ potting containers. As shown in Table 4 (Model 2), the WTP estimates for all of these non-conventional potting containers were found to be higher and statistically significant for individuals with higher EC scores $(\$ 0.255, \$ 0.143$, and $\$ 0.175$ for compostable, plantable, and recyclable, respectively). In contrast, only the compostable potting container was statistically significant in the model with lower EC scores (Table 5, Model 6). These results tend to support our Hypothesis 3 that individuals scoring high (above-average) on the EC scale would be WTP a higher price premium for plants in environmentally friendly potting containers.

Although the results for the model with higher EC scores (Model 2) showed that individuals were willing to pay higher premiums for non-conventional potting containers compared with the base model, further analysis showed that the WTP estimates differ depending on the individuals' orientations of the EC. For instance, individuals scoring above average (i.e., above 3.89 score) on the egoistic orientation of the EC were willing to pay a $\$ 0.241$ price premium for compostable containers, whereas no premium (or discount) exists for the plantable and recyclable containers. In other words, individuals who are concerned about the environment for their own reasons (e.g., "concerns my own health, my own future") are not willing to pay a price premium. Furthermore, individuals with above-average 
Table 4. Comparison of WTP estimates for plants and plant attributes between base model and models with higher scores in EC orientations.

\begin{tabular}{|c|c|c|c|c|c|}
\hline & Model 1 (base model) & Model 2 (EC-total score) & Model 3 (EC-egoistic) & Model 4 (EC-altruistic) & Model 5 (EC-biospheric) \\
\hline \multirow[t]{2}{*}{ Basil } & -0.280 & -0.171 & -0.051 & 0.003 & -0.006 \\
\hline & {$[-0.371,-0.19]$} & {$[-0.284,-0.059]$} & {$[-0.187,0.085]$} & {$[-0.127,0.134]$} & {$[-0.127,0.115]$} \\
\hline Sustainable & {$[-0.111,0.092]$} & {$[-0.125,0.132]$} & {$[-0.135,0.18]$} & {$[-0.13,0.173]$} & {$[-0.115,0.166]$} \\
\hline \multirow[t]{2}{*}{ Energy-saving } & 0.131 & 0.148 & 0.138 & 0.143 & 0.148 \\
\hline & {$[0.029,0.232]$} & {$[0.019,0.278]$} & {$[-0.02,0.297]$} & {$[-0.01,0.295]$} & {$[0.006,0.29]$} \\
\hline \multirow[t]{2}{*}{ Compostable } & 0.227 & 0.255 & 0.241 & 0.272 & 0.269 \\
\hline & {$[0.124,0.33]$} & {$[0.123,0.386]$} & {$[0.08,0.401]$} & {$[0.117,0.427]$} & {$[0.125,0.413]$} \\
\hline \multirow[t]{2}{*}{ Plantable } & 0.122 & 0.143 & 0.099 & 0.131 & 0.128 \\
\hline & {$[0.021,0.224]$} & {$[0.013,0.272]$} & {$[-0.059,0.256]$} & {$[-0.021,0.283]$} & {$[-0.013,0.269]$} \\
\hline \multirow[t]{2}{*}{ Recyclable } & 0.155 & 0.175 & 0.114 & 0.162 & 0.169 \\
\hline & {$[0.053,0.257]$} & {$[0.045,0.305]$} & {$[-0.043,0.272]$} & {$[0.01,0.315]$} & {$[0.027,0.311]$} \\
\hline Locally produced & 0.222 & 0.288 & 0.324 & 0.344 & 0.309 \\
\hline
\end{tabular}

$95 \%$ confidence intervals are provided in brackets.

$\mathrm{WTP}=$ willingness to pay; $\mathrm{EC}=$ environmental concern.

Table 5. Comparison of WTP estimates for plants and plant attributes between base model and models with lower scores in EC orientations.

\begin{tabular}{|c|c|c|c|c|c|}
\hline & Model 1 (base model) & Model 6 (EC-total score) & Model 7 (EC-egoistic) & Model 8 (EC-altruistic) & Model 9 (EC-biospheric) \\
\hline \multirow[t]{2}{*}{ Tomato } & 0.180 & 0.003 & -0.208 & -0.238 & -0.173 \\
\hline & {$[0.078,0.283]$} & {$[-0.155,0.161]$} & {$[-0.468,0.052]$} & {$[-0.464,-0.012]$} & {$[-0.357,0.011]$} \\
\hline \multirow[t]{2}{*}{ Basil } & -0.280 & -0.46 & -0.963 & -0.861 & -0.738 \\
\hline & {$[-0.371,-0.19]$} & {$[-0.61,-0.31]$} & {$[-1.269,-0.657]$} & {$[-1.112,-0.609]$} & {$[-0.933,-0.543]$} \\
\hline \multirow[t]{2}{*}{ Sustainable } & -0.009 & -0.043 & -0.092 & -0.101 & -0.081 \\
\hline & {$[-0.111,0.092]$} & {$[-0.201,0.115]$} & {$[-0.35,0.165]$} & {$[-0.323,0.121]$} & {$[-0.263,0.102]$} \\
\hline \multirow[t]{2}{*}{ Energy-saving } & 0.131 & 0.084 & 0.081 & 0.082 & 0.102 \\
\hline & {$[0.029,0.232]$} & {$[-0.074,0.243]$} & {$[-0.176,0.338]$} & {$[-0.14,0.304]$} & {$[-0.081,0.284]$} \\
\hline \multirow[t]{2}{*}{ Water-saving } & 0.036 & 0.024 & 0.026 & 0.048 & 0.034 \\
\hline & {$[-0.065,0.137]$} & {$[-0.134,0.182]$} & {$[-0.23,0.283]$} & {$[-0.174,0.269]$} & {$[-0.148,0.216]$} \\
\hline \multirow[t]{2}{*}{ Compostable } & 0.227 & 0.183 & 0.217 & 0.177 & 0.167 \\
\hline & {$[0.124,0.33]$} & {$[0.023,0.343]$} & {$[-0.044,0.478]$} & {$[-0.047,0.401]$} & {$[-0.016,0.351]$} \\
\hline \multirow[t]{2}{*}{ Plantable } & 0.122 & 0.090 & 0.099 & 0.069 & 0.097 \\
\hline & {$[0.021,0.224]$} & {$[-0.068,0.249]$} & {$[-0.159,0.356]$} & {$[-0.153,0.291]$} & {$[-0.086,0.28]$} \\
\hline \multirow[t]{2}{*}{ Recyclable } & 0.155 & 0.126 & 0.199 & 0.148 & 0.109 \\
\hline & {$[0.053,0.257]$} & {$[-0.033,0.285]$} & {$[-0.061,0.459]$} & {$[-0.075,0.371]$} & {$[-0.074,0.291]$} \\
\hline \multirow[t]{2}{*}{ Locally produced } & 0.222 & 0.112 & -0.020 & 0.022 & 0.049 \\
\hline & {$[0.132,0.312]$} & {$[-0.026,0.249]$} & {$[-0.242,0.202]$} & {$[-0.17,0.214]$} & {$[-0.109,0.207]$} \\
\hline \multirow[t]{2}{*}{ Imported } & -1.518 & -1.031 & -0.925 & -0.892 & -0.953 \\
\hline & {$[-1.683,-1.353]$} & {$[-1.241,-0.821]$} & {$[-1.252,-0.599]$} & {$[-1.17,-0.613]$} & {$[-1.187,-0.718]$} \\
\hline
\end{tabular}

$95 \%$ confidence intervals are provided in brackets.

$\mathrm{WTP}=$ willingness to pay; $\mathrm{EC}=$ environmental concern.

altruistic (3.96) and biospheric (3.81) scores were willing to pay price premiums for both compostable (\$0.272 and \$0.269) and recyclable (\$0.162 and \$0.169) potting containers. Contrary to the results for Models 3 to 5 (i.e., based on the subsample with aboveaverage EC-egoistic, EC-altruistic, and ECbiospheric scores), the results for Models 7 , 8 , and 9 (i.e., based on the subsample with below-average EC-egoistic, EC-altruistic, and EC-biospheric scores) were not significant. Thus, Hypothesis 4 that WTP for environmentally friendly potting containers differs by egoistic, altruistic, and biospheric orientations of the EC was supported given the WTP differences among egoistic, altruistic, and biospheric orientations for recyclable/ compostable containers as well as the differences between high and low EC scoring groups.

WTP for origin of production-related attributes. As expected, the results in the base model (Table 4) showed that individuals were willing to pay a $\$ 0.222$ premium for locally produced plants with a $\$ 1.518$ discount for imported plants (Table 4). In Model 2 , the participants were willing to pay a $\$ 0.288$ price premium for locally produced, whereas they discounted imported (as opposed to plants produced within the country) by $\$ 1.765$. Although the price discount was sizable in Model 6, it was considerably lower (\$1.031) compared with that of Model 2 (\$1.765). Therefore, Hypothesis 5 that individuals with higher EC total scores would require higher price discounts for imported plants and would be willing to pay higher premiums for locally produced plants was supported.

When examining the egoistic, altruistic, and biospheric groups associated with the respondents with "above-average" EC scores (Models 3, 4, and 5), the results are comparable to Model 2 in terms of general directions of the WTP estimates. In other words, all three orientations of the EC are based on statistically significant coefficients and positive for locally produced (ranging from $\$ 0.309$ to $\$ 0.344$ ) and negative for the imported attribute (ranging from $-\$ 1.964$ to -\$1.813). Meanwhile, in Models 7, 8, and 9 (i.e., models with lower egoistic, altruistic, and biospheric scores), none of the WTP estimates for locally produced plants was based on significant coefficients. In addition, price discounts for the "imported" attribute in Models 7, 8, and 9 were significant but considerably lower $(-\$ 0.925,-\$ 0.892$, and $-\$ 0.953$, respectively) than those of Models 3,4 , and 5 , i.e., those with higher scores in egoistic, altruistic, and biospheric orientations $(-\$ 1.813,-\$ 1.964$, and $-\$ 1.928$, respectively). Thus, Hypothesis 6 that WTP and price discounts vary based on individuals' EC orientations was also supported.

The results from models with the "belowaverage" EC score subsample are in striking contrast to those of the "above-average" EC 
score subsample, which were willing to pay for several environmentally friendly labels and potting containers. Furthermore, the lack of a premium for locally produced is quite interesting given the amount of state/province and firm-level resources being put into "buy local" campaigns.

\section{Conclusions}

The present study contributes to the consumer choice behavior literature by integrating psychometric measures (i.e., EC scale) into the WTP modeling framework by demonstrating that in addition to product attributes and demographic characteristics, WTP estimates may vary based on differences in the extent to which individuals are concerned about environmental issues. Given the increased awareness and demand for environmentally friendly product attributes, it is essential for firms to understand how EC impacts WTP for proenvironmental attributes such as sustainable production practices, biodegradable and recyclable potting containers, and locally grown plants.

This research provided evidence that the survey participants were willing to pay a premium for selected horticultural product attributes that address eco-concerns, but the results suggest that not all eco-motivations produce similar WTP. Individuals with higher EC total scores would be willing to pay higher price premiums for proenvironmental productionrelated attributes such as energy-saving practices, but the WTP for production methods differed depending on the orientation of individuals' ECs (i.e., egoistic concerns, altruistic concerns, and biospheric concerns). Individuals scoring high on the EC scale would be willing to pay higher price premiums for plants in environmentally friendly potting containers and also require higher price discounts for imported plants but be willing to pay higher premiums for locally produced plants.

Industry professionals can take this information and adapt it to their own proximate markets by communicating proenvironmental messages to certain consumer types. For consumers with high EC-biospheric and altruistic scores, container choices appear to be a crucial part of their WTP premiums because they showed higher WTP premiums for compostable and recyclable containers compared with individuals with a high EC-egoistic score. Production practices had lower WTP premiums than many container choices and location of production. A premium is possible for plants grown using energy conservation practices and is highest for consumers with high EC biospheric scores. Communicating reduction in heat, electric, and fuel consumption may appeal to those consumers but with less potential payback period. Disseminating information regarding location of production, energy-conserving production practices, and alternative container use may cost relatively little compared with the potential price premium that may be charged.

\section{Literature Cited}

Behe, B.K., B.L. Campbell, C.R. Hall, H Khachatryan, and J.H. Dennis. 2013. Consumer preferences for local and sustainable plant characteristics. HortScience 48:200-208.

Behe, B.K., R.M. Walden, M. Duck, B. Cregg, K. Kelley, and R.D. Lineberger. 2005a. Consumer preferences for and cost of production of tabletop Christmas trees. HortScience 40:409-412.

Behe, B.K., J. Hardy, S. Barton, J. Brooker, T. Fernandez, C. Hall, J. Hicks, R. Hinson, P. Knight, R. McNiel, T. Page, B. Rowe, C. Safley, and R. Schutzki. 2005b. Landscape plant material, size, and design sophistication increase perceived home value. J. of Env. Hort. 23:127-133.

Blend, J.R. and E.O. van Ravenswaay. 1999 Measuring consumer demand for ecolabeled apples. Amer. J. Agr. Econ. 81:1078-1083.

Boyle, K.J., T.P. Holmes, M.F. Teisl, and B. Roe. 2001. A comparison of conjoint analysis response formats. Amer. J. Agr. Econ. 83:441454.

Campbell, B.L., S. Mhlanga, and I. Lesschaeve. Perception versus reality: Canadian consumer views of local and organic. Canadian J. of Agr. Econ. DOI: 10.1111/j.1744-7976.2012.01267.x (forthcoming).

de Groot, J.I.M. and L. Steg. 2008. Value orientations to explain beliefs related to environmental significant behavior: How to measure egoistic, altruistic, and biospheric value orientations. Environ. Behav. 40:330-354.

de Groot, J.I.M. and L. Steg. 2010. Relationships between value orientations, self-determined motivational types and pro-environmental behavioural intentions. J. Environ. Psychol. 30:368-378.

Dillman, D., J. Smyth, and L. Christian. 2009. Internet, mail, and mixed-mode surveys: The tailored design method. John Wiley \& Sons, Inc., Hoboken, NJ.

Frechette, G. 2001. Random-effects ordered probit. Stata Tech. Bull. 59:23-27.

Greene, W.H. 2012. Econometric analysis. 7th Ed. Prentice Hall, Upper Saddle River, NJ.

Hall, C.R. 2010. Making cents of green industry economics. HortTechnology 20:832-835.

Hall, C.R., B.L. Campbell, B.K. Behe, C. Yue, R.G. Lopez, and J.H. Dennis. 2010. The appeal of biodegradable packaging to floral consumers. HortScience 45:583-591.

Hansla, A., A. Gamble, A. Juliusson, and T. Gärling. 2008. The relationships between awareness of consequences, environmental concern, and value orientations. J. Environ. Psychol. 28:1-9.

IBISWorld Reports. 2013a. Nursery and Garden Stores in the US: Industry report 44422. 14 Aug. 2013. <http://clients1.ibisworld.com/reports/us/ industry/default.aspx?entid=1037>.

IBISWorld Reports. 2013b. Florists in the US: Industry report 45311. 14 Aug. 2013. <http:// clients1.ibisworld.com/reports/us/industry/ default.aspx?entid $=1096>$.
Lawless, H.T. and H. Heyman. 1999. Sensory evaluation of food: Principles and practices. Aspen Publishers, Inc., Gaithersburg, MD.

Loureiro, M.L., J.J. McCluskey, and R.C. Mittelhammer. 2001. Assessing consumer preferences for organic, eco-labeled and regular apples. J. of Agr. and Res. Econ. 26:404-416.

Mason, S., T. Starman, R.D. Lineberger, and B.K Behe. 2008. Consumer preferences for price, color harmony and care information of container gardens. HortScience 43:380-384.

Milfont, T.L., J. Duckitt, and C. Wagner. 2010. A cross-cultural test of the value-attitudebehavior hierarchy. J. Appl. Soc. Psychol. 40: 2791-2813

Moon, W., W.J. Florkowski, B. Brückner, and I. Schonhof. 2002. Willingness to pay for environmental practices: Implications for ecolabeling. Land Econ. 78:88-102.

Rabe-Hesketh, S., A. Pickles, and C. Taylor. 2000. Generalized linear latent and mixed models. Stata Tech. Bull. 53:47-57.

Royne, M.B., M. Levy, and J. Martinez. 2011. The public health implications of consumers' environmental concern and their willingness to pay for an eco-friendly product. J. Consum. Aff. 45:329-343.

Schultz, P. 2001. The Structure of environmental concern: Concern for self, other people, and the biosphere. J. Environ. Psychol. 21:327-339.

Schultz, W.P., V.V. Gouveia, L.D. Cameron, G. Tankha, P. Schmuck, and M. Franek. 2005. Values and their relationship to environmental concern and conservation behavior. J. Cross Cult. Psychol. 36:457-475.

Sribney, W. 1995. Random-effects probit. Stata Tech. Bull. 26:15-18.

Stern, P.C. 2000. Toward a coherent theory of environmentally significant behavior. J. Soc. Issues 56:407-424.

Stern, P.C. and T. Dietz. 1994. The value basis of environmental concern. J. Soc. Issues 50:6584.

Stern, P.C., T. Dietz, T. Abel, G. Guagnano, and L. Kalof. 1999. A value-belief-norm theory of support for social movements: The case of environmentalism. Hum. Ecol. Rev. 6:81-97.

Stern, P.C., T. Dietz, and L. Kalof. 1993. Value orientations, gender, and environmental concern. Environ. Behav. 25:322-348.

Weigel, R.H. 1983. Environmental attitudes and the prediction of behavior. In: Feimer, N.R. and E.S. Geller (eds.). Environmental psychology: Directions and perspectives. Praeger, New York, NY.

Weigert, A.J. 1997. Self, interaction, and natural environment: Refocusing our eyesight. State University of New York Press, New York, NY.

Wessells, C.R., R.J. Johnston, and H. Donath. 1999. Assessing consumer preferences for eco-labeled seafood: The influence of species, certifier and household attributes. Amer. J. Agr. Econ. 81:1084-1089.

Yue, C., C.R. Hall, B.K. Behe, B.L. Campbell, J.H. Dennis, and R. Lopez. 2010. Are consumers willing to pay more for biodegradable containers than for plastic ones? J. of Agr. and Applied Econ. 42:757-772.

Zagaden, Y., B.K. Behe, and R. Gough. 2008. Consumer preferences for native plants in Montana residential landscapes and perceptions for naturalistic designs. J. of Env. Hort. 26:109-114. 